\title{
CONTROLADORIA MUNICIPAL: PESQUISA-AÇÃO SOBRE SUAS FUNÇÕES COM BASE LEGAL E NA LITERATURA
}

\author{
Bruno Cristiano Neves Stédile ${ }^{1}$, Alexandre de Freitas Carneiro², José Moreira da Silva \\ Neto $^{3}$, José Arilson de Souza ${ }^{4}$
}

\section{RESUMO}

Este estudo tem por objetivo analisar a percepção de servidores sobre as funções da Controladoria Geral de um Município, contidas na lei de criação do órgão, em comparação às descritas na literatura, por meio de uma pesquisa-ação participante. A ação foi realizada em três fases: uso de questionário, discussão participante e um checklist final. Os resultados mostraram um desconhecimento, por parte de alguns servidores, da lei de criação e das nove funções iniciais da CGM. Após a ação e reflexão participantes, concluiu-se que são 24 as funções da Controladoria. Houve discordância, em relação ao encontrado na literatura, quanto às funções de Sistemas de Informações e Sistemas de Custos. Este trabalho defende que são 26 funções, ao incluírem-se essas duas mencionadas. Percebeu-se a existência de uma assimetria informacional interna em relação à teoria da agência.

Palavras-chave: Controladoria Municipal. Funções. Pesquisa-ação. Teoria da Agência.

\section{MUNICIPAL CONTROLLERSHIP: ACTION RESEARCH ON ITS FUNCTIONS ACCORDING TO LEGAL BASIS AND TO THE LITERATURE}

\begin{abstract}
This study aims at analyzing the perception of employees about the functions of the General Controllership of a municipality (GCM), as stated in the law that created it, comparing to the ones that appear in the literature, through a participatory action research. The action was performed in three stages - with the use of a questionnaire, participant discussion and a final checklist. The results showed that some employees have a lack of awareness of the law of creation and of the nine initial functions stated in the law. After the participatory action and after the reflection, the study concluded that there are 24 functions for the Controllership. There was a disagreement with the literature regarding the functions of the Information System and of the System of Costs. This study supports that there are 26 functions, including those two mentioned previously. There is an internal informational asymmetry related to the theory of the agency.
\end{abstract}

Keywords: Municipal Controllership. Functions. Action research. Agency theory.

\footnotetext{
${ }^{1}$ Universidade Federal de Rondônia

${ }^{2}$ Universidade Federal de Rondônia

${ }^{3}$ Universidade Federal de Rondônia

${ }^{4}$ Universidade Federal de Rondônia 


\section{INTRODUÇÃO}

Na sociedade pós-moderna, um dos desafios para os gestores públicos é a clareza na prestação de contas e na transparência dos atos governamentais. A Controladoria é uma ferramenta que pode contribuir para se alcançar a excelência no serviço público, proporcionando qualidade na geração, interpretação e disseminação de informações econômico-financeiras dos entes públicos. Ela torna-se essencial uma vez que, através de um sistema de controle interno bem estruturado e em efetivo exercício, é possível se obter informação contábil com veracidade.

A Controladoria, se bem estruturada e organizada, torna os sistemas de controle um instrumento fundamental ao gestor que, ao ter em mãos informações úteis e tempestivas, poderá tomar a melhor decisão em benefício da sociedade, o que lhe proporciona maior segurança.

A Lei n. ${ }^{\circ} 4.320 / 64$, que dispõe sobre as normas para a elaboração dos orçamentos da União, Estados e Municípios, já alertava os administradores para a importância do controle interno integrado. Com a Lei Complementar n. ${ }^{\circ}$ 101/00, fica demonstrada a intenção do legislador de cada vez mais fortalecer a transparência dos processos e ampliar o controle das contas públicas.

Para o gestor, é de suma importância a implantação de um controle interno eficiente, pois, antes de tudo, ele responde com seus bens e sua reputação pelos atos que realiza ou transfere para que outro realize em seu nome. Esse profissional precisa ter segurança nas informações que obtém e precisa estabelecer critérios de controle em todos os níveis e, de forma antecipada, dar amparo a todos os atos que pratica. Não há, assim, como separar o controle interno da ação de gerenciar.

A relevância de se estudar o tema da Controladoria no setor público reside no fato de que se verifica uma carência de estudos contemporâneos e de publicações em periódicos sobre o assunto. Lunkes et al. (2012) e Durigon e Diehl (2013) notam que não há muitos trabalhos sobre a Controladoria; Peleias et al. (2010) defende que não há uma elite de pesquisadores dedicados ao tema. Também, Cruz et al. (2014) concluíram que desde a criação da Controladoria Geral da União (em 2003), a disseminação de seu modelo aos municípios do país ainda é incipiente. Verifica-se, portanto, necessidade de mais pesquisas desse tema.

Dessa forma, a questão que se procura responder nesta pesquisa é: qual a percepção dos servidores da Controladoria Geral do Município de Vilhena, Rondônia, sobre as funções exercidas pelo órgão, com base na sua lei de criação, e sobre as funções estabelecidas pela 
literatura, bem como sobre quais ações serão importantes para a modernização desse setor, visando a uma nova formação informacional da gestão municipal? Este estudo tem por objetivo analisar a percepção de servidores sobre as funções da Controladoria Geral de um Município, contidas na lei de criação do órgão, em comparação às descritas na literatura, por meio de uma pesquisa-ação participante. Em estudo anterior no Estado de Rondônia, Silva, Carneiro e Ramos (2015) identificaram entre os quatro maiores municípios que têm suas funções definidas em sua lei de criação e que mais se adéquam àquelas definidas na literatura, que são: Porto Velho (capital), Ji-Paraná, Ariquemes e Vilhena. Este último é o lócus da presente pesquisa com uma ação participante com os servidores do órgão de controle interno.

O artigo está estruturado em outras cinco seções, para além desta introdução. Na seção 2, a Controladoria governamental é descrita; a seção 3 trata sobre a teoria da agência e a assimetria informacional; a seção 4 expõe os procedimentos metodológicos do trabalho; a pesquisa-ação e os resultados são apresentados na seção 5 e as considerações, as limitações e as sugestões de pesquisas futuras, na seção 6 .

\section{CONTROLADORIA GOVERNAMENTAL}

Conforme afirma Castro (2010), historicamente, a palavra 'controle' sempre esteve ligada às finanças. A atividade de controle ligada inicialmente às finanças das empresas pode ser aplicada às finanças pessoais. O equilíbrio do orçamento individual depende do controle que se exerce sobre os gastos, de forma a compatibilizá-los com a receita. Esse princípio consolidou-se na Administração Pública por meio da Lei de Responsabilidade Fiscal. Segundo essa lei, deve-se manter o controle orçamentário da coisa pública, por ser um recurso da sociedade, regulado por agentes públicos em favor da coletividade.

O controle é visto como um instrumento da democracia. Já a Declaração dos Direitos Humanos e do Cidadão, de 1789, em seu art. 15, afirma que "a sociedade tem o direito de pedir contas a todo agente público sobre sua administração".

Silva (2004) explica que, com a promulgação da Constituição de 1988, embora os aspectos da legalidade e da formalidade ainda continuassem sendo foco dos órgãos de controle interno e externo, surgiram noções inovadoras que substituíram, gradualmente, os sistemas tradicionais e, por conseguinte, a contabilidade e a auditoria passaram a estar mais voltadas para aspectos gerenciais. A Controladoria passa a ser o órgão responsável pelo controle interno na organização. Também, segundo o entendimento desse autor, a Contabilidade deve estar inserida na estrutura da Controladoria, e não na função fazendária. 
Segundo Slomski (2007), 'controladoria' é um termo de difícil definição. Para esse autor, pode-se afirmar, no entanto, que o conceito passa pela busca de se atingir a excelência em qualquer esfera, seja ela pública ou privada, e, para além disse, algo mais, procurado pelo conjunto de elementos que compõe a máquina de qualquer entidade. Esse autor também complementa que não há como continuar a administrar baseando-se no achismo, modelo no qual o gestor público acha que a população precisa de algo. Para Catelli (2012), a Controladoria é uma unidade administrativa dinâmica que tem a missão de coordenar a gestão econômica da organização pública, visando a aperfeiçoar o resultado econômico.

A Lei n. ${ }^{\circ} 4.320 / 64$, em seus artigos 75 a 80, detalha um conjunto de procedimentos que pretendem servir de base à melhoria do controle interno exercido pelo Poder Executivo. De acordo com a Instrução Normativa SFC n. ${ }^{\circ}$ 01/01,

o controle interno administrativo é o conjunto de atividades, planos, rotinas, métodos e procedimentos interligados, estabelecidos com vistas a assegurar que os objetivos das unidades e entidades da administração pública sejam alcançados, de forma confiável e concreta, evidenciando eventuais desvios ao longo da gestão até a consecução dos objetivos fixados pelo poder público.

Para Piscitelli, Timbó e Rosa (2014), o Sistema de Controle Interno (SCI) é o responsável pelo acompanhamento físico e econômico de projetos e atividades. Assim, é possível efetuar ajustes na despesa orçamentária e no custo da execução das obras. O controle interno abrange as atividades de avaliação do cumprimento das metas previstas no Plano Plurianual, da execução dos programas de governo e dos orçamentos e de avaliação de gestão dos administradores públicos. Também segundo esses autores, o sistema de controle interno deverá manter solidamente o compromisso com a tríade moralidade, cidadania e justiça social. Trata-se de um processo de democratização do Poder para o verdadeiro cliente - (o cidadão) -, que já não suporta mais ver tantos desvios e desperdícios dos recursos públicos. Segundo Silva (2012), a atenção dirigida ao controle interno está diretamente ligada à responsabilidade do gestor e ao risco para o patrimônio público.

Monteiro (2015) elaborou uma categorização da importância do SCI e totalizou cinco categorias: gestão do risco, informação, comportamento ético, imagem da entidade, e proteção dos recursos públicos. Esse autor identificou também que a falta de uma cultura e gestão ao risco alinhada com a carência de pessoal em número adequado e com a qualidade técnica exigida são as principais barreiras identificadas para a implantação do SCI.

Azevedo e Conceição (2015) investigaram o conjunto de atribuições do controller nas organizações empresariais. O perfil de funções encontrado nessa abordagem empírica revelou 
que esse profissional está ligado a tarefas de planejamento operacional e estratégico, custos, tributos, controle interno, monitoramento e avaliação dos sistemas de informações. Já no estudo empírico de Lunkes, Schnorrenberger e Silva da Rosa (2013), as funções consolidadas da controladoria são as de planejamento, controle, contábil e elaboração de relatórios e interpretação. Para Wrigth, Callado e Melo (2013), como atividades da controladoria no setor público, segundo servidores da Controladoria Geral da União, devem ser consideradas a coordenação de um sistema de controle interno, promoção da transparência pública, o estímulo ao controle social e o desenvolvimento de políticas e procedimentos de controle. E, segundo Casagrande, Bratti e Casagrande (2015), é indispensável e pressuposto básico para o funcionamento do SCI a realização de seus trabalhos por técnicos capacitados.

Lunkes e Schnorrenberger (2009) elaboraram um mapa conceitual da controladoria, conforme mostra a Figura 1.

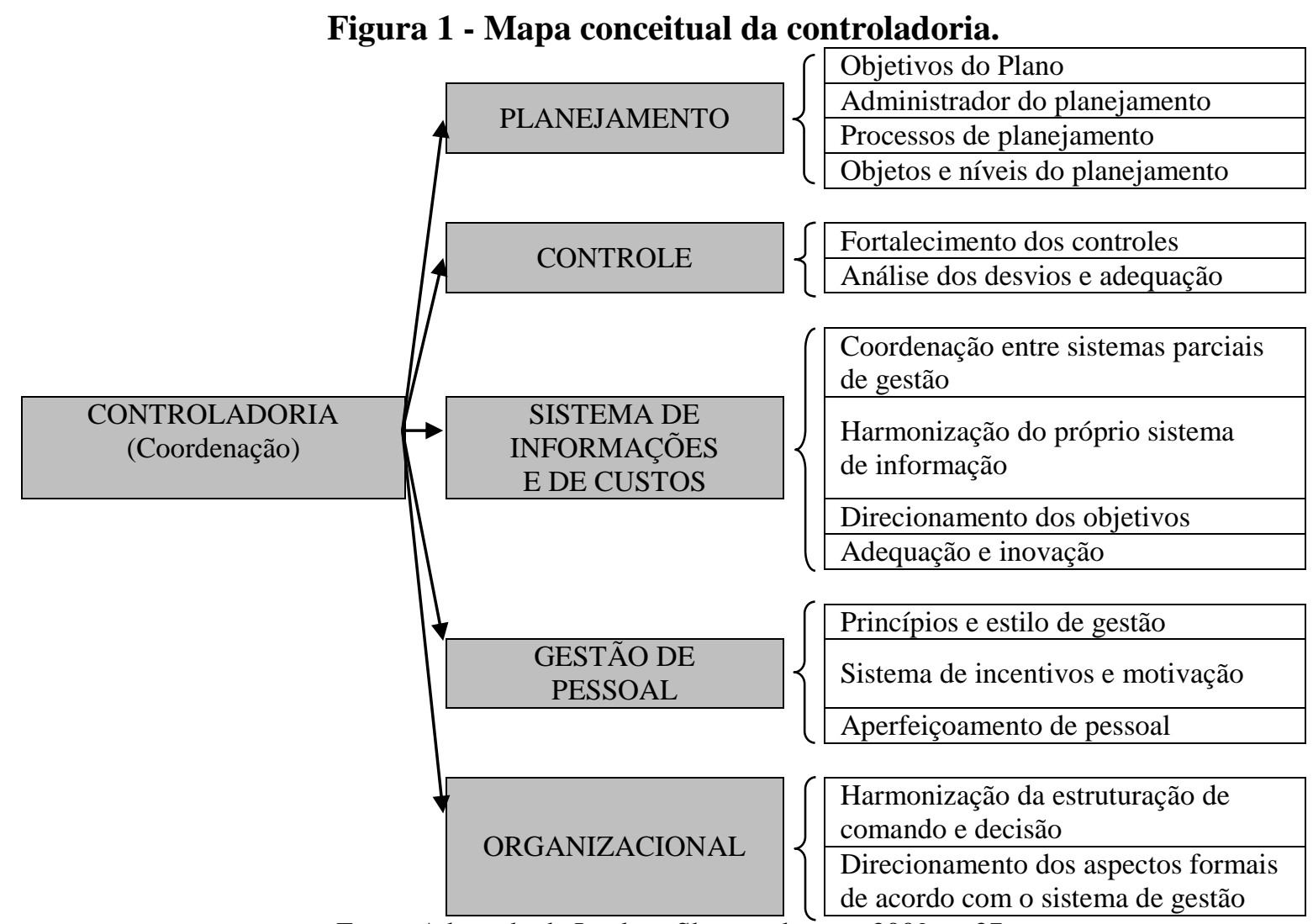

Fonte: Adaptado de Lunkes; Shnorrenberger, 2009, p. 37.

Conforme Lunkes e Schnorrenberger (2009), o sistema de informações gera dados que acompanham todas as fases do planejamento e controle. Esse sistema proporciona, assim, um suporte imprescindível aos gestores. De acordo com a Decisão Normativa n. ${ }^{\circ}$ 001/2015, do Tribunal de Contas do Estado de Rondônia (TCE-RO), em seu capítulo V, art. 12, inciso XIV, 
é atribuição da Controladoria instituir e manter o sistema de informações para o exercício das atividades finalísticas do Sistema de Controle Interno. Também de acordo com Slomski (2007, p. 16), "não dá para pensar em controladoria dissociada de sistemas de informações estruturados". Para Schmidt, Santos e Martins (2014), o sistema de custos também é função da controladoria.

Suzart, Marcelino e Rocha (2011) elaboraram um construto com as atividades da controladoria pública agrupadas por funções que estão apresentadas no Quadro 1. A essas funções são agregadas as de sistemas de informações e de sistema de custos, conforme a literatura.

Quadro 1 - Atividades da controladoria agrupadas por funções.

\begin{tabular}{|c|c|c|}
\hline FUNÇÃO & ATIVIDADES & FONTE \\
\hline Contábil & $\begin{array}{l}\text { Acompanhar/fiscalizar a gestão contábil, financeira e orçamentária. } \\
\text { Elaborar demonstrações contábeis. } \\
\text { Elaborar e manter atualizado o plano de contas do ente federado. } \\
\text { Gerenciar a contabilidade do ente federado. }\end{array}$ & \multirow{6}{*}{$\begin{array}{l}\text { Suzart, Marcelino e } \\
\text { Rocha (2011). }\end{array}$} \\
\hline $\begin{array}{l}\text { Gerencial- } \\
\text { estratégica }\end{array}$ & $\begin{array}{l}\text { Acompanhar/fiscalizar a gestão administrativa/operacional. } \\
\text { Avaliar resultados de planos, de orçamentos e de programas públicos. } \\
\text { Propor medidas para racionalizar o uso dos recursos públicos. }\end{array}$ & \\
\hline Tributária & Supervisionar a arrecadação e a despesa do ente federado. & \\
\hline $\begin{array}{l}\text { Proteção e } \\
\text { controle } \\
\text { dos ativos }\end{array}$ & Acompanhar/fiscalizar a gestão patrimonial. & \\
\hline $\begin{array}{l}\text { Controle } \\
\text { interno }\end{array}$ & $\begin{array}{c}\text { Apoiar os órgãos de controle externo. } \\
\text { Planejar, coordenar e executar as funções de controle interno. } \\
\text { Planejar, coordenar e executar as funções de corregedoria. } \\
\text { Planejar, coordenar e executar as funções de ouvidoria. } \\
\text { Zelar pela observância dos princípios da administração pública. }\end{array}$ & \\
\hline $\begin{array}{l}\text { Controle de } \\
\text { riscos }\end{array}$ & $\begin{array}{l}\text { Avaliar a execução dos contratos de gestão. } \\
\text { Prevenir e combater a corrupção. }\end{array}$ & \\
\hline $\begin{array}{l}\text { Sistema de } \\
\text { Informações }\end{array}$ & $\begin{array}{l}\text { Aperfeiçoamento dos sistemas de planejamento e programação } \\
\text { financeira. } \\
\text { Integração do sistema de controle ao sistema geral de informações. } \\
\text { Função de auxílio à tomada de decisão. }\end{array}$ & $\begin{array}{c}\text { Silva (2004); } \\
\text { Slomski (2007); } \\
\text { Lunkes e } \\
\text { Schnorrenberger (2009); } \\
\text { Meller, Lopes e Lunkes } \\
\text { (2014). }\end{array}$ \\
\hline $\begin{array}{l}\text { Sistema de } \\
\text { Custos }\end{array}$ & $\begin{array}{l}\text { Estimular os gestores públicos na implantação de sistema de custos } \\
\text { como forma de minimizar a assimetria informacional entre o Estado e } \\
\text { a sociedade. } \\
\text { Função de fornecimento e interpretação de dados. }\end{array}$ & $\begin{array}{l}\text { Slomski (2007); } \\
\text { Meller, Lopes e Lunkes } \\
\text { (2014). }\end{array}$ \\
\hline
\end{tabular}

Fonte: Adaptado de Suzart, Marcelino e Rocha, 2011.

Conforme afirma Slomski (2007), é urgente que o controller instigue os gestores públicos a implantarem sistemas de custos nas entidades públicas brasileiras, como forma de redução da assimetria informacional entre o Estado e a sociedade - aquele informa e esta não entende. A controladoria tem um papel fundamental para essa redução, de acordo com Slomski (2007) e Cavalcante e De Luca (2013). Slomski (2007) ainda afirma que o balanço social é outro instrumento útil que pode ser desenvolvido para diminuir tal assimetria. 


\section{TEORIA DA AGÊNCIA E ASSIMETRIA INFORMACIONAL}

A teoria de agenciamento (agency theory), segundo Slomski (2007), procura explicar a relação existente entre o principal e o agente. Ela surgiu, segundo Cosenza, Alegría e Laurencel (2011, p. 130), “de uma corrente de pensamento na literatura econômica que enfatizava a necessidade de se conhecer a realidade da empresa, a partir dos problemas associados à delegação de autoridade e à tomada de decisão”. Ainda para Slomski (2007), em $1^{\circ}$ estágio, no Estado, o cidadão é o principal e o governante o agente; em $2^{\circ}$ estágio o governante é o principal e os secretários o agente; em $3^{\circ}$ estágio os secretários são os principais e os diretores de área os agentes e em $4^{\circ}$ estágio os diretores de área os principais e os servidores públicos os agentes. Esse autor afirma que o Estado e suas entidades, nesse contexto, são vistos e analisados sob a perspectiva da teoria dos contratos. Para Brousseau (1993), os custos de contratação são baseados em contratos, que são entendidos como acordos por meio dos quais os agentes se obrigam uns aos outros a ceder ou a apropriar, criar ou não certas coisas.

De acordo com Hitt, Ireland e Hoskisson (1999), uma relação de agência existe quando uma parte delega a responsabilidade de tomada de decisão a uma segunda parte, por uma contrapartida. Sendo assim, os problemas passam a existir quando um agente toma decisões que resultam em conflitos com os objetivos e interesses do principal. Logo, a relação principal-agente pode levar ao oportunismo administrativo, entendido como um conjunto de atitudes ou comportamentos ilícitos em relação à entidade, na busca de interesses pessoais.

Rozo (2003) explica que a teoria da agência relaciona-se às não conformidades que surgem numa relação de contrato, formal ou informal, quando as partes contratantes possuem informação assimétrica e incerta. O autor ressalta a existência do mercado e de formas institucionais capazes de encerrar os contratos para reduzir tais não conformidades.

Para Slomski (1999), é conexo afirmar que as entidades públicas devem ser vistas sob o ponto de vista da teoria da agência, pois, ao se analisar o Estado e suas entidades sob o prisma de contratos que representam, observa-se nitidamente a existência de uma relação de agência, devido à presença de três condições indispensáveis: o gestor público (agente) dispõe de vários comportamentos possíveis de serem seguidos; a ação do gestor público (agente) compromete o bem-estar das duas partes; as ações do gestor público (agente) possivelmente não serão observadas pelo cidadão (principal), existindo, assim, assimetria informacional. 
Como consequência, fica a dúvida se o gestor público (agente) tomará a decisão correta que trará melhor benefício para o cidadão (principal).

Ainda segundo Slomski (2003), considerando que o Estado é uma organização com inúmeros contratos complexos entre os donos desses recursos econômicos (principal) e os gestores públicos (agente), que são responsáveis pelo uso e controle desses recursos, é necessário criar modelos para maximizar a compreensão dessa relação - modelos que permitam ao cidadão analisar o valor produzido pelos agentes.

Para Akdere e Azevedo (2006), a assimetria informacional acontece quando a capacidade do principal de acompanhar o trabalho e as ações do agente fica prejudicada, impossibilitada ou rompida por outros fatores conhecidos apenas pelo agente.

Esses pontos de vista deixam clara a existência de um problema de comunicação entre agente e principal, Estado e sociedade, aumentando a incerteza da população sobre o que acontece no interior da coisa pública. A sociedade não possui tanta riqueza de informações quanto o agente, dificultando, assim, o monitoramento das ações por parte do cidadão. Isso gera uma "assimetria informacional externa dado que o cidadão não sabe com certeza se o agente está maximizando o retorno de seu capital na produção de bens e serviços como seria de desejar" (SLOMSKI, 2007, p. 33).

Da mesma forma, há também a assimetria informacional interna, dado que os servidores públicos possuem maior riqueza de informação do que o gestor eleito. De fato, o gestor "não tem informações suficientes para saber com exatidão se todos os componentes da cadeia agente-principal, nos mais diversos estágios, estão seguindo as suas diretrizes, a fim de alcançar a maximização que deseja e prestar contas ao cidadão" (SLOMSKI, 2007, p. 33). Dessa forma, pode "não ser possível monitorar todas as atitudes dos agentes, haverá uma assimetria informacional" (SLOMSKI, 2007, p. 34).

\section{MÉTODO}

\subsection{Caracterização metodológica}

Vergara (2014) classifica as pesquisas quanto aos fins e aos meios. O preparo metodológico utilizado classifica-se quanto aos fins como pesquisa aplicada e, quanto aos meios, pesquisa de campo e pesquisa-ação. O método utilizado neste trabalho foi o da pesquisa-ação participante. Esse método demanda clareza na definição de objetivos em relação à pesquisa, à ação, à maneira como cada participante é investigado. A maneira como cada um se comportou com relação ao compromisso com a mudança necessária tornou-se 
primordial para responder concretamente à questão levantada. A intenção, ao se utilizar tal metodologia, é obter uma orientação para o futuro (THIOLLENT, 2009), facilitando a criação de soluções voltadas para um porvir desejável, promovendo reflexões quanto às funções da Controladoria.

Segundo Thiollent (2009), no transcorrer da pesquisa-ação, acontece um efeito de aprendizagem, às vezes concebido como conscientização. Os participantes e pesquisadores aprendem, em conjunto, a identificar e resolver problemas e a aprendizagem é difundida ao longo do processo (Figura 2).

Figura 2 - Relações entre pesquisa, ação, aprendizagem e avaliação.

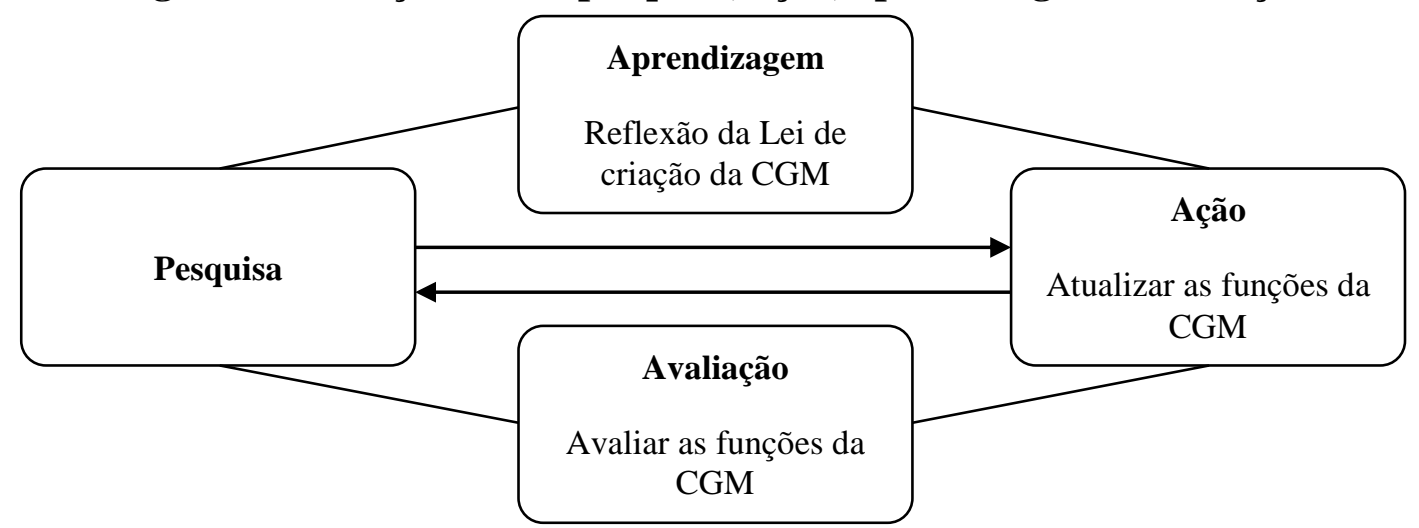

Fonte: Adaptado de Thiollent, 2009, p. 46.

A ação desta pesquisa é a de avaliar e atualizar as funções da Controladoria Geral do Município - CGM descritas na Lei n. ${ }^{o}$ 1.622/03 de criação da CGM de Vilhena, em comparação às funções descritas na literatura.

Tripp (2005) considera a pesquisa-ação uma variedade de investigação-ação, na qual se empregam técnicas de pesquisa visando informar o planejamento e a avaliação das melhoras obtidas. De acordo com esse autor, há vários tipos de pesquisa-ação e a deste trabalho é a pesquisa-ação política, pois nele reflete-se sobre a promoção da mudança de uma cultura institucional e/ou suas limitações.

Existem várias razões que podem tornar a pesquisa-ação atrativa, segundo French (2009). Ela permite aos praticantes pesquisar a sua própria atividade profissional, ajuda a melhorar a prática no local de trabalho, capacita os gestores em competências multidisciplinares e ajuda-os efetivamente a implementarem mudanças.

\subsection{Locus, etapas e técnica de coleta e análise dos dados}


O locus da pesquisa foi a Controladoria Geral do Município (CGM) de Vilhena, que é composta por 21 servidores. Os procedimentos metodológicos foram divididos em três fases. Na primeira fase, foi elaborado e aplicado questionário versando sobre as funções da CGM, de acordo com a Lei n. ${ }^{\circ}$ 1.622/03 (SUZART; MARCELINO; ROCHA, 2011), e ainda sobre os Sistemas de Custos e Sistema de Informação, buscando verificar a percepção dos servidores em relação a essas temáticas. Depois de identificar as funções da CGM na lei de criação do órgão de controle interno, criaram-se quatro blocos de questões. A segunda fase caracterizou-se por discussões participantes e em grupo. As respostas foram organizadas e apresentadas aos servidores numa nova data. Cada questão e cada resposta foram comentadas e discutidas, com o objetivo de se obter a participação dos servidores e conhecer o que pensa quem executa as funções e enfrenta as dificuldades da CGM no dia a dia. Levaram-se em consideração a Lei n. ${ }^{0}$ 1.622/03, as funções da CGM, segundo Suzart, Marcelino e Rocha (2011), os Sistema de Custos e Sistemas de Informações, conforme a literatura, e a percepção dos servidores. Na terceira e última fase, foi apresentado um checklist com um novo modelo de funções para a Controladoria, mais amplo, atualizado e de acordo a literatura. Esse modelo foi colocado à apreciação dos servidores, com base na ação a ser executada, ampliando a abrangência de atuação e com o intuito de atualizar a lei municipal que ampara as funções da CGM.

A análise dos dados foi realizada pela triangulação dos dados coletados, de forma interpretativa pelo pesquisador e através de discussão com os pesquisados.

A pesquisa-ação revela o "não dito" da organização. Ela almeja introduzir mudanças na percepção dos participantes e até mesmo na cultura da entidade. É uma maneira de questionar certas situações, de forma a trazer auxílio e para a busca de respostas coletivas.

\section{PESQUISA-AÇÃO}

\subsection{Dados gerais}

Após a autorização do Controlador Geral, a aplicação do questionário, primeira etapa deste trabalho, foi realizada no dia 17 de abril de 2015, nas dependências do órgão, onde estão lotados 21 servidores assim distribuídos: um servidor está cedido ao Instituto de Previdência Municipal de Vilhena - IPMV; um está de licença não remunerada pelo período de dois anos; um é o responsável pela limpeza; dois servidores trabalham na recepção (a eles não foi entregue o questionário); três se recusaram a responder, sendo que, destes, dois alegaram falta de conhecimento e um alegou não ter tempo; um é o controlador e um é o auditor. Dos 21 
servidores, 12 participaram da ação. O questionário também foi aplicado na Câmara de Vereadores, que possui apenas um servidor - o próprio Controlador, totalizando 13 participantes na pesquisa.

Antes da entrega dos questionários, foi ressaltada a importância do compromisso e da responsabilidade de cada participante para o sucesso da pesquisa. Só com essa colaboração seria possível alcançar os objetivos de adquirir conhecimento e atingir as mudanças necessárias apontadas pela ação. Pediu-se, assim, que todos participassem com ética. As respostas foram organizadas em planilhas. No Quadro 2, apresenta-se o perfil dos servidores participantes da ação.

Quadro 2 - Dados gerais.

\begin{tabular}{|c|c|c|c|}
\hline FAIXA ETÁRIA & QUANTIDADE & TEMPO NA CGM & QUANTIDADE \\
\hline Até 30 anos & 3 & Menos de 01 (um) ano & 3 \\
\hline De 31 a 35 anos & 0 & Entre 01 (um) e 05 (cinco) anos & 5 \\
\hline De 36 a 40 anos & 1 & De 06 (seis) a 10 (dez) anos & 2 \\
\hline De 41 a 50 anos & 2 & De 11 (onze) a 20 (vinte) anos & 1 \\
\hline Acima de 50 anos & 2 & Mais de 20 anos & 0 \\
\hline GENNERO & QUANTIDADE & TIPO DE VÍNCULO & QUANTIDADE \\
\hline Masculino & 5 & Efetivo & 8 \\
\hline Feminino & 6 & Cargo comissionado & 2 \\
\hline $\begin{array}{l}\text { FORMAÇÃO } \\
\text { ACADÊMICA }\end{array}$ & QUANTIDADE & Cedido de outro órgão & 0 \\
\hline Graduação & 5 & Prazo determinado & 0 \\
\hline Especialização - em curso & 3 & & \\
\hline Especialização - concluída & 3 & & \\
\hline Mestrado & 0 & & \\
\hline Doutorado & 0 & & \\
\hline
\end{tabular}

Fonte: Dados da pesquisa (2015).

Durante a organização das respostas do questionário foi observado que nem todos os 13 participantes responderam a todas as questões, assim sendo, o somatório das respostas nem sempre será 13 .

\subsection{Primeira fase}

Inicialmente, verificaram-se as funções da Controladoria Geral do Município de Vilhena de acordo com a Lei n. ${ }^{\circ}$ 1.622/2003, lei de criação. Essas funções são: I - avaliar o cumprimento das metas previstas no plano plurianual e na Lei de Diretrizes Orçamentárias, bem como a execução dos programas de governo e dos orçamentos do Estado e dos Municípios; II - comprovar a legalidade e avaliar os resultados quanto à eficácia da gestão orçamentária, financeira e patrimonial nos órgãos e entidades da administração estadual e municipal bem como da aplicação de recursos públicos por entidade de direito privado; III exercer o controle das operações de crédito, avais e garantias, bem como dos direitos e 
haveres do Estado e dos Municípios; IV - fiscalizar o cumprimento do disposto na Lei Complementar n. ${ }^{\circ}$ 101/2000; V - fiscalizar o cumprimento dos percentuais de aplicação na educação e saúde fixadas pela Constituição Federal; VI - verificar a destinação dos recursos obtidos com a alienação de ativos, tendo em vista as restrições constitucionais e as da Lei Complementar n. ${ }^{\circ}$ 101/2000; VII - dar ciência ao Chefe do Poder Executivo e ao Tribunal de Contas do Estado de Rondônia de qualquer irregularidade que tomar conhecimento; VIII emitir relatório sobre as contas do Poder Executivo, seus fundos e autarquias, que deverá ser assinado pelo Controlador Geral e a Gerência de Contabilidade, juntamente com o Prefeito Municipal e o Secretário Municipal de Fazenda; e IX - apoiar o Controle Externo no exercício de sua missão institucional.

Na primeira fase da pesquisa, no bloco I de questões, foi perguntado aos servidores da CGM se as funções listadas na Lei n. ${ }^{\circ} 1.622 / 03$ estão sendo executadas atualmente. É importante ressaltar que, na aplicação do questionário, houve servidores que indagaram que lei seria essa, evidenciando desconhecimento, o que pode denotar a existência de assimetria informacional interna. As respostas aos questionários são apresentadas no Quadro 3.

\section{Quadro 3 - Funções da CGM de acordo com a Lei n. ${ }^{\circ}$ 1.622/03.}

\begin{tabular}{|c|c|c|c|}
\hline ITENS & BLOCO I & SIM & NÃO \\
\hline I & $\begin{array}{l}\text { Avaliar o cumprimento das metas previstas no plano plurianual, na Lei de Diretrizes } \\
\text { Orçamentárias, bem como a execução dos programas de governo e dos orçamentos do } \\
\text { Estado e dos Municípios. }\end{array}$ & 12 & 0 \\
\hline II & $\begin{array}{l}\text { Comprovar a legalidade e avaliar os resultados quanto à eficácia da gestão orçamentária, } \\
\text { financeira e patrimonial nos órgãos e entidades da administração estadual e municipal } \\
\text { bem como da aplicação de recursos públicos por entidade de direito privado. }\end{array}$ & 10 & 2 \\
\hline III & $\begin{array}{l}\text { Exercer o controle das operações de crédito, avais e garantias, bem como dos direitos e } \\
\text { haveres do Estado e dos Municípios. }\end{array}$ & 6 & 5 \\
\hline IV & Fiscalizar o cumprimento do disposto na Lei Complementar $n^{\circ} 101 / 2000$. & 13 & 0 \\
\hline V & $\begin{array}{l}\text { Fiscalizar o cumprimento dos percentuais de aplicação na educação e saúde fixadas pela } \\
\text { Constituição Federal. }\end{array}$ & 12 & 0 \\
\hline VI & $\begin{array}{l}\text { Verificar a destinação dos recursos obtidos com a alienação de ativos, tendo em vista as } \\
\text { restrições constitucionais e as da Lei Complementar } n^{\circ} 101 / 2000 \text {. }\end{array}$ & 9 & 2 \\
\hline VII & $\begin{array}{l}\text { Dar ciência ao Chefe do Poder Executivo e ao Tribunal de Contas do Estado de } \\
\text { Rondônia de qualquer irregularidade que tomar conhecimento. }\end{array}$ & 6 & 6 \\
\hline VIII & $\begin{array}{l}\text { Emitir relatório sobre as contas do Poder Executivo, seus fundos e autarquias, que deverá } \\
\text { ser assinado pelo Controlador Geral e a Gerência de Contabilidade, juntamente com o } \\
\text { Prefeito Municipal e o Secretário Municipal de Fazenda. }\end{array}$ & 12 & 0 \\
\hline IX & Apoiar o Controle Externo no exercício de sua missão institucional. & 13 & 0 \\
\hline
\end{tabular}

Fonte: Dados da pesquisa (2015).

Nota-se que as funções listadas na Lei n. ${ }^{\circ}$ 1.622/03 estão sendo executadas pela CGM de Vilhena, de modo geral. Porém para as funções III e VII há um equilíbrio nas respostas 'sim’ e 'não'. Isso evidencia que, na percepção dos servidores, não há um consenso com 
relação a essas duas funções e evidencia o desconhecimento de alguns sobre o art. 74 da $\mathrm{CF} / 88$.

Na função VII é possível detectar um problema de assimetria informacional interna, uma vez que $50 \%$ dos servidores afirmam não informar os gestores quando detectadas as irregularidades.

Conforme o modelo proposto, as funções da Controladoria, de acordo com Suzart, Marcelino e Rocha (2011), são aquelas que constam no Quadro 1, apresentado anteriormente. Com a finalidade de apresentar o modelo proposto por Suzart, Marcelino e Rocha (2011), que amplia a área de atuação da Controladoria, no bloco II, foi questionado aos participantes, primeiramente, se estas novas funções fazem parte do rol de atribuição CGM e, em seguida, se estão sendo executadas pela ela. O resultado é apresentado no Quadro 4.

\section{Quadro 4 - Funções da CGM de acordo com Suzart, Marcelino e Rocha (2011).}

\begin{tabular}{|c|l|c|c|c|c|}
\hline \multirow{2}{*}{ ITENS } & \multicolumn{1}{|c|}{ BLOCO II } & \multicolumn{2}{c|}{ Faz parte } & \multicolumn{2}{c|}{ Executa } \\
\cline { 3 - 6 } & & SIM & NÃO & SIM & NÃO \\
\hline I & Acompanhar/fiscalizar a gestão contábil, financeira e orçamentária. & 13 & 0 & 12 & 0 \\
\hline II & Elaborar demonstrações contábeis. & 5 & 8 & 3 & 9 \\
\hline III & Elaborar e manter atualizado o plano de contas do ente federado. & 5 & 6 & 5 & 6 \\
\hline IV & Gerenciar a contabilidade do ente federado. & 7 & 4 & 5 & 5 \\
\hline V & Acompanhar/fiscalizar a gestão administrativa/operacional. & 11 & 1 & 11 & 1 \\
\hline VI & Avaliar resultados de planos, de orçamentos e de programas públicos. & 11 & 0 & 10 & 1 \\
\hline VII & Propor medidas para racionalizar o uso dos recursos públicos. & 8 & 4 & 8 & 4 \\
\hline VIII & Supervisionar a arrecadação e a despesa do ente federado. & 9 & 2 & 8 & 3 \\
\hline IX & Acompanhar/fiscalizar a gestão patrimonial. & 12 & 0 & 10 & 2 \\
\hline X & Apoiar os órgãos de controle externo. & 12 & 0 & 12 & 0 \\
\hline XI & Planejar, coordenar e executar as funções de controle interno. & 12 & 0 & 12 & 0 \\
\hline XII & Planejar, coordenar e executar as funções de corregedoria. & 6 & 4 & 6 & 4 \\
\hline XIII & Planejar, coordenar e executar as funções de ouvidoria. & 2 & 8 & 2 & 8 \\
\hline XIV & Zelar pela observância dos princípios da administração pública. & 12 & 0 & 12 & 0 \\
\hline XV & Avaliar a execução dos contratos de gestão. & 11 & 1 & 10 & 2 \\
\hline XVI & Prevenir e combater a corrupção. & 12 & 0 & 10 & 2 \\
\hline
\end{tabular}

Fonte: Dados da pesquisa (2015).

De acordo com a percepção da maioria dos servidores, os itens II e III não são função e não são executadas pela CGM. Na função IV houve resposta dividida demonstrando que não há concordância sobre essa função entre os servidores. Alguns respondentes entendem que essa não é função da Controladoria, no entanto, Silva (2004) entende que a Contabilidade deve estar inserida na sua estrutura. Os servidores também afirmam que item XIII não é função e não é executada pela CGM, confirmando o problema de assimetria informacional. Ainda os itens VII e XII obtiveram opiniões divididas.

O Sistema de Informação (SI), de acordo com o Tribunal de Contas do Estado de Rondônia (2015) e com Suzart, Marcelino e Rocha (2011), é função da Controladoria. O bloco III questiona os participantes quanto ao Sistema de Informação. 
Quadro 5 - Sistema de informação.

\begin{tabular}{|c|l|c|c|}
\hline & \multicolumn{1}{|c|}{ BLOCO III } & SIM & NÃO \\
\hline I & Você concorda que o SI é função da Controladoria? & 4 & 7 \\
\hline II & A Controladoria desenvolve ou está desempenhando esta função? Se não, por quê?? & $\begin{array}{c}\text { Falta de recursos } \\
\text { humanos, de interesse, } \\
\text { interesse dos gestores. }\end{array}$ \\
\hline III & O módulo de Controle Interno do sistema de informações é utilizado? & 2 & 9 \\
\hline
\end{tabular}

Fonte: Dados da pesquisa (2015).

Para os servidores, o SI não é função da Controladoria. Entre as razões citadas para isso está a falta de interesse, inclusive por parte do gestor, e de recursos humanos. A percepção dos servidores contraria a orientação do Tribunal de Contas do Estado de Rondônia, que afirma que o SI é responsabilidade da Controladoria, que deve instituí-lo e mantê-lo. Ainda de acordo com a literatura, Slomski (2007) afirma que não dá para pensar numa controladoria dissociada dos sistemas de informações. A empresa que fornece softwares e que cuida da manutenção do sistema para o município dispõe do módulo "Controle Interno", que oferece acesso a relatórios gerenciais para acompanhamento de informações tempestivas que poderiam auxiliar os trabalhos da Controladoria. Esse módulo, porém, não é utilizado pelos servidores.

O Sistema de Custo é de grande importância e pode trazer benefícios relevantes para o município, uma vez que minimiza a assimetria informacional existente entre a sociedade e o Estado (SLOMSKI, 2007) e estimula a busca pela economicidade almejada através da teoria da agência, buscando a excelência no cumprimento do papel de gestor na relação de contrato entre principal e agente. No bloco IV, os participantes responderam sobre o Sistema de Custos. Os resultados são apresentados no Quadro 6.

\section{Quadro 6 - Sistema de Custos.}

\begin{tabular}{|c|l|c|c|}
\hline & \multicolumn{1}{|c|}{ BLOCO IV } & SIM & NÃO \\
\hline I & O Sistema de Custos é função da Controladoria? & 4 & 6 \\
\hline II & Há Sistemas de Custos ou estão em fase de implantação no município? & 4 & 6 \\
\hline III & A Controladoria desenvolve este controle na prática? Se não, por quê?? & $\begin{array}{c}\text { Falta de recursos } \\
\text { humanos, equipamentos } \\
\text { e recursos financeiros. }\end{array}$ \\
\hline
\end{tabular}

Fonte: Dados da pesquisa (2015).

No entendimento dos servidores da CGM, o Sistema de Custos não faz parte das funções da Controladoria, sendo as justificativas a falta de recursos humanos, a falta de equipamentos e de recursos financeiros. O Sistema de Custo é uma ferramenta primordial nas atividades de uma Controladoria, pois abre horizontes para a modernização administrativa tão almejada para o setor público. 


\subsection{Segunda fase}

A segunda fase inicia-se com a intenção de provocar uma discussão, participação e reflexão a respeito das funções da Controladoria, a partir da percepção dos servidores. Essa fase ocorreu no dia 2 de outubro de 2015. Nele, foram apresentados aos servidores da CGM os resultados obtidos com a aplicação do questionário, começando com os dados gerais e o perfil dos servidores.

Em seguida, foram apresentados os resultados do bloco I, que diz respeito às funções da CGM de acordo com a Lei n. ${ }^{\circ}$ 1.622/03, lei de criação do órgão no município de Vilhena. Nas observações dos servidores, é constatado que o controle das operações de créditos, avais e garantias, bem como dos direitos e haveres do município, não é feito. Os funcionários alegaram que esse controle já chega pronto à CGM e que não há tempo para análises. Outra verificação é a destinação dos recursos obtidos com a alienação de ativos, tendo em vista as restrições constitucionais e as da Lei Complementar n. ${ }^{\circ}$ 101/00 - o que não é efetuado. Com relação a dar ciência ao Chefe do Poder Executivo e ao Tribunal de Contas do Estado de Rondônia sobre qualquer irregularidade de que tomarem conhecimento, os servidores afirmaram que ao Chefe do Executivo, sim, se reportam, mas não ao do Tribunal de Contas não, devido à falta de autonomia. Em relação às demais funções, de acordo com o art. $6 .^{\circ}$ da Lei n. ${ }^{\circ}$ 1.622/03, todos concordaram que se trata de incumbências da CGM.

Em relação às questões do bloco II, que se referem a funções propostas por Suzart, Marcelino e Rocha (2011), os resultados revelam que os servidores não concordam que elaborar demonstrações contábeis seja função deles. Para os entrevistados, tal função pertence à Contabilidade, que é subordinada à Secretaria Municipal de Fazenda. Foi perguntado, então, se não seria o caso de a Contabilidade estar subordinada à CGM. Os servidores responderam que não, pois o órgão já possui um contador e não há, portanto, necessidade disso. Na percepção dos servidores, a CGM apenas acompanha a Contabilidade do município e não tem autonomia para gerenciá-la.

Com relação ao acompanhamento/fiscalização da gestão administrativa/operacional, os servidores concordam que tal função é da competência da CGM. Contudo, afirmam que ela não está sendo executada em sua totalidade devido à falta de estrutura. Quando foi questionado o que seria essa estrutura, foram citadas várias situações como falta de pessoal, falta de espaço físico, falta de um veículo para efetuarem auditorias in loco com o efeito 
surpresa, falta de combustível e falta de material, inclusive materiais básicos, como impressora.

Com relação à avaliação dos resultados de planos, de orçamentos e de programas públicos, os servidores afirmam que é habitual a emissão de instruções normativas orientando como atingir os melhores resultados e reiteram a falta de estrutura citada anteriormente. Esses servidores possuem cargos comissionados e funções gratificadas e deixam a entender que podem perder esses cargos e funções dependendo da atitude que tomem. Outra das situações levantadas é que não há dispositivos para que se possam aplicar penalidades quando identificadas as irregularidades. As auditorias, quando solicitadas, são barradas. A CGM até requer abertura de processo administrativo para apuração e tomada de conta, mas não há mecanismos de punição. Ainda no âmbito das dificuldades já expostas, os servidores deixaram claro que tentam planejar, coordenar e executar as funções de controle interno.

Com relação à ouvidoria, os servidores entendem que não ela é competência da CGM, mas acabam por realizá-la. Afirmaram também que a auditoria avalia a execução dos contratos de gestão. Em relações aos demais itens do bloco II, os servidores concordam que se trata de incumbências do órgão.

Sobre o bloco III, os servidores entendem que o SI não é função da CGM - apenas o acompanhamento das informações o é. Eles alegam que há falta de recursos humanos e de interesse dos gestores em gerenciar um sistema de informação. No bloco IV, sobre o Sistema de Custos, os servidores citam que cada secretaria precisa ter seu controle interno e seu sistema de custos e afirmam que a contabilidade não é função da CGM. Cada secretaria tem um gerente que deve ser o responsável pelo seu sistema de custos.

Os servidores relatam, mais uma vez, os problemas com materiais básicos como impressora e computador. Os relatórios são elaborados, mas não conseguem ser despachados pelo gestor e não são bem vistos por ele. Devido à falta de estrutura, as auditorias são comprometidas, pois, para que ocorram, é necessário solicitar veículo e combustível de outra secretaria, prejudicando, assim, o efeito surpresa. O gestor orienta a administração a não nomear cargos comissionados sem necessidade, o que pode onerar os cofres públicos. Diante da atual situação financeira e econômica do país, os servidores advertem sobre a necessidade de contenção de despesas e, mesmo com todas as dificuldades, deixam claro que a CGM alerta quando há algo em desconformidade e que existe neles muita vontade de trabalhar e de fazer o correto. 
A teoria da agência, vista sob a ótica da relação de contratos, contribuiria para o aprimoramento dos sistemas de informação e do sistema de custos, buscando, assim, bons resultados e a efetividade da administração pública. Porém, não é isso o que os servidores pensam, pois afirmam, tanto no questionário, quanto na reunião, que implantar e manter o SI não são funções da CGM, contrariando até mesmo a Decisão Normativa n. ${ }^{\circ}$ 01/15 do TCERO. Deixa-se, assim, de utilizar uma ferramenta importante e primordial no dia a dia e que resolveria muitos dos problemas enfrentados pela Controladoria.

\subsection{Terceira e última fase}

Para concluir a ação, foi elaborado um checklist contendo as funções da CGM, de acordo com a Lei n. ${ }^{\circ}$ 1.622/03 e da literatura. Esse checklist (Quadro 7) foi apresentado aos participantes como resultado das fases anteriores e foi proposto um novo conjunto de funções, com a intenção de atualizar a lei municipal quanto às funções da CGM de Vilhena. Foi solicitada a opinião dos entrevistados em relação a esse conjunto - essas seriam ou não funções do órgão? Nesse último encontro, participaram dez dos 21 servidores.

\section{Quadro 7 - Checklist das funções da CGM.} FUNÇÕES

\begin{tabular}{|c|c|c|}
\hline FUNÇÕES & SIM & NÃO \\
\hline $\begin{array}{l}\text { 1. Avaliar o cumprimento das metas previstas no plano plurianual e na Lei de Diretrizes } \\
\text { Orçamentárias, bem como a execução dos programas de governo do Município. }\end{array}$ & 10 & 0 \\
\hline $\begin{array}{l}\text { 2. Comprovar a legalidade e avaliar os resultados quanto à eficácia da gestão orçamentária, } \\
\text { financeira e patrimonial nos órgãos e entidades da administração municipal, bem como da } \\
\text { aplicação de recursos públicos por entidade de direito privado. }\end{array}$ & 10 & 0 \\
\hline $\begin{array}{l}\text { 3. Exercer o controle das operações de crédito, avais e garantias, bem como dos direitos e } \\
\text { haveres do Município. }\end{array}$ & 8 & 2 \\
\hline 4. Fiscalizar o cumprimento do disposto na Lei Complementar n. ${ }^{\circ} 101 / 2000$. & 10 & 0 \\
\hline $\begin{array}{l}\text { 5. Fiscalizar o cumprimento dos percentuais de aplicação na educação e saúde fixados pela } \\
\text { Constituição Federal. }\end{array}$ & 10 & 0 \\
\hline $\begin{array}{l}\text { 6. Verificar a destinação dos recursos obtidos com a alienação de ativos, tendo em vista as } \\
\text { restrições constitucionais e as da Lei Complementar } n^{\circ} 101 / 2000 \text {. }\end{array}$ & 10 & 0 \\
\hline $\begin{array}{l}\text { 7. Dar ciência ao Chefe do Poder Executivo e ao Tribunal de Contas do Estado de Rondônia } \\
\text { de qualquer irregularidade que tomar conhecimento. }\end{array}$ & 10 & 0 \\
\hline $\begin{array}{l}\text { 8. Emitir relatório sobre as contas do Poder Executivo, seus fundos e autarquias, que deverá } \\
\text { ser assinado pelo Controlador Geral e pela Gerência de Contabilidade, juntamente com o } \\
\text { Prefeito Municipal e o Secretário Municipal de Fazenda. }\end{array}$ & 10 & 0 \\
\hline 9. Apoiar o Controle Externo no exercício de sua missão institucional. & 10 & 0 \\
\hline 10. Acompanhar/fiscalizar a gestão contábil, financeira e orçamentária. & 10 & 0 \\
\hline 11. Elaborar demonstrações contábeis. & 5 & 5 \\
\hline 12. Elaborar e manter atualizado o plano de contas do ente federado. & 6 & 4 \\
\hline 13. Gerenciar a contabilidade do ente federado. & 7 & 3 \\
\hline 14. Acompanhar/fiscalizar a gestão administrativa/operacional. & 10 & 0 \\
\hline 15. Avaliar resultados de planos, de orçamentos e de programas públicos. & 10 & 0 \\
\hline 16. Propor medidas para racionalizar o uso dos recursos públicos. & 10 & 0 \\
\hline 17. Supervisionar a arrecadação e a despesa do ente federado. & 10 & 0 \\
\hline 18. Acompanhar/fiscalizar a gestão patrimonial. & 10 & 0 \\
\hline 19. Planejar, coordenar e executar as funções de controle interno. & 10 & 0 \\
\hline
\end{tabular}




\begin{tabular}{|l|c|c|}
\hline 20. Planejar, coordenar e executar as funções de corregedoria. & 6 & 4 \\
\hline 21. Planejar, coordenar e executar as funções de ouvidoria. & 6 & 4 \\
\hline 22. Zelar pela observância dos princípios da administração pública. & 10 & 0 \\
\hline 23. Avaliar a execução dos contratos de gestão. & 9 & 1 \\
\hline 24. Prevenir e combater a corrupção. & 10 & 0 \\
\hline 25. Implantar e manter o Sistema de Informações. & 1 & 9 \\
\hline 26. Implantar e manter o Sistema de Custos. & 1 & 9 \\
\hline
\end{tabular}

Fonte: Dados da pesquisa (2015).

\section{CONSIDERAÇÕES FINAIS}

Este estudo teve por objetivo analisar a percepção de servidores sobre as funções da Controladoria Geral de um Município, contidas na lei de criação do órgão, em comparação às descritas na literatura, por meio de uma pesquisa-ação participante. Para tal, a ação da pesquisa foi avaliar e atualizar as funções da CGM, conforme descritas na Lei n. ${ }^{\circ} 1.622 / 03$, lei de criação do órgão, em cotejo com as funções descritas na literatura.

Na percepção dos servidores da CGM, as funções da Controladoria, de acordo com o Quadro 7, seriam as de números 1 a 24 . Portanto, seriam essas as funções para modificar a lei de criação. Dessa forma, a pesquisa-ação foi de utilidade para promover mudança e reflexão. Na percepção do pesquisador, o Sistema de Informações e o Sistema de Custos são funções da Controladoria, o que perfaz um total de 26 funções do órgão.

O resultado revelou a existência de assimetria informacional interna e, por isso, em conflito com a teoria da agência. De acordo com a literatura, as ferramentas para minimizar tal assimetria seriam um adequado Sistema de Informações e Sistema de Custos. Identificouse que não há concordância, por parte dos servidores, que os Sistemas de Informações e Sistemas de Custos sejam funções da Controladoria. Inclusive, no sistema contábil geral, existe um módulo denominado Controle Interno que não é utilizado pela CGM. Alguns servidores também desconheciam as nove funções da CGM, conforme listadas em sua lei de criação, de 2003. A Decisão Normativa n. ${ }^{\circ}$ 001/15 do TCE-RO também determina que é atribuição da Controladoria instituir e manter o sistema de informações para o exercício das atividades finalísticas do Sistema de Controle Interno. Isso denota desconhecimento da determinação do órgão de controle externo.

Destaca-se a afirmação da literatura de que a Controladoria pública é recente e as pesquisas apontaram que não há muitas publicações, nem uma elite de pesquisadores sobre o tema. Considerando que sua obrigatoriedade nos municípios é recente e a própria 
Controladoria Geral da União foi criada em 2003, percebe-se que há um vasto espaço para debates sobre o tema.

Como limitação da pesquisa, considerou-se a falta de conhecimento, a formação acadêmica e o fato dos servidores serem nomeados em cargo em comissão/função gratificada. Como recomendação de ordem prática, indica-se a atualização da Lei n. ${ }^{\circ}$ 1.622/03 e adaptação das funções do órgão de acordo com o Quadro 7 e que a Contabilidade seja incluída na estrutura da Controladoria Geral do Município.

O estudo é de interesse para gestores públicos, contadores, auditores, controladores, bem como para todos os cidadãos interessados na instrumentalização do controle social e na transparência da gestão pública.

\section{REFERÊNCIAS}

AKDERE, M.; AZEVEDO, R. E. Agency theory implications for efficient contracts in organization development. Organization Development Journal. Chesterlan, v. 24, n. 2, p. 43-54, Summer, 2006. Proquest ABI/Inform Global.

AZEVEDO, W. M.; CONCEIÇÃO, S. H. Teoria versus prática: afinal qual é o papel do controller nas organizações? In: $6 .^{\circ}$ Congresso UFSC de Controladoria e Finanças \& Iniciação Científica em Contabilidade. Anais... UFSC. Florianópolis, 2015.

BRASIL. Constituição (1988). Constituição da República Federativa do Brasil. Brasília: Senado, 2004.

Lei Complementar n. ${ }^{\circ}$ 101, de 4 maio 2000. Lei de Responsabilidade Fiscal. Estabelece normas de finanças públicas voltadas para a responsabilidade na gestão fiscal. Disponível em: <http://www.planalto.gov.br/ccivil_03/leis/lcp/lcp101.htm>. Acesso em: 10 nov. 2015.

Lei n. ${ }^{\circ}$ 4.320, de 17 de março de 1964. Estatui Normas Gerais de Direito Financeiro para elaboração e controle dos orçamentos e balanços da União, dos Estados, dos Municípios e do Distrito Federal. Disponível em: 〈http://www.planalto.gov.br/ccivil_03/leis/14320.htm>. Acesso em: 10 nov. 2015.

Instrução Normativa n. ${ }^{0}$ 01, de 06 de abril de 2001. Define diretrizes, princípios, conceitos e aprova normas técnicas para a atuação do Sistema de Controle Interno do Poder Executivo Federal. Disponível em: $<$ http://www.cgu.gov.br/sobre/legislacao/arquivos/instrucoes-normativas/in-0106042001.pdf/view>. Acesso em: 16 dez. 2015.

BROUSSEAU, E. Les théories dês contrats: une revue. Revue d'Economie Politique, v. 103, n. 1, p. 1-82, jan./feb. 1993. 
CASAGRANDE, M. D. H.; BRATTI, C.; CASAGRANDE, J. L. Controle interno e formação dos profissionais que atuam nos municípios da Amures. ReFAE - Revista da Faculdade de Administração e Economia, São Paulo, v. 6, n. 2, p. 155-181, 2015.

CASTRO, D. P. Auditoria, contabilidade e controle interno no setor público. 3. ed. São Paulo: Atlas, 2010.

CATELLI, A. Visão da controladoria aplicada ao setor público: criando valor para a sociedade. In: MACHADO, N. et al. GBRSP - Gestão baseada em resultado no setor público: uma abordagem para implementação em prefeituras, câmaras municipais, autarquias, fundações e unidades organizacionais. São Paulo: Atlas, 2012.

CAVAlCANTE, M. C. N.; DE LUCA, M. M. M. Controladoria como instrumento de governança no setor público. Revista de Educação e Pesquisa em Contabilidade, Brasília, v. 7, n. 1, 73-90, jan./mar. 2013.

COSENZA, J. P.; ALEGRÍA, A. I. Z.; LAURENCEL, L. C. Implicações da caracterização principal-agente nas abordagens de preços de transferência. Contabilidade Vista \& Revista, UFMG, Belo Horizonte, v. 22, n. 3, p. 127-162, jul./set. 2011.

CRUZ, M. C. M. T.; SPINELli, M. V. C.; SILVA, T. A. B.; CARVAlHO, M. A. T. Controle interno em municípios brasileiros: uma análise das controladorias-gerais dos municípios diante do modelo da Controladoria-Geral da União. Revista de Gestión Pública, v. III, n. 2, Julio-Diciembre, pp. 297-328, 2014.

DECLARAÇÃO DOS DIREITOS HUMANOS E DO CIDADÃO. 26 de agosto de 1789. Disponível em: <http://www.direitoshumanos.usp.br/index.php/Documentos-anteriores\%C3\%A0-cria\%C3\%A7\%C3\%A3o-da-Sociedade-das-Na\%C3\%A7\%C3\%B5es-at\%C3\%A91919/declaracao-de-direitos-do-homem-e-do-cidadao-1789.html>. Acesso em: 15 dez. 2015.

DURIGON, A. R.; DIEHL, C. A. Controladoria no setor público: uma análise dos artigos publicados no Congresso USP de Controladoria e Contabilidade - período de 2001 a 2011. Contabilidade Vista \& Revista, UFMG, Belo Horizonte, v. 24, n. 2, p. 91-109, abr./jun. 2013.

FRENCH, S. Action research for practising managers. Journal of Management Development, v. 28, n. 3, p. 187-204, 2009.

HITT, M. A.; IRELAND, R. D.; HOSKISSON, R. E. Strategic management: competitiveness and globalization - concepts and cases. 3. ed. Cincinato-Ohio: SouthWestern College Publishing, 1999.

LUNKES, R. J.; SCHNORRENBERGER, D. Controladoria: na coordenação dos sistemas de gestão. São Paulo: Atlas, 2009.

LUNKES, R. J. et al. Análise da legitimidade sociopolítica e cognitiva da controladoria no Brasil. Revista Contabilidade \& Finanças. USP. São Paulo, v. 23, n. 59, p. 89-101, 2012. 
LUNKES, R. J.; SCHNORRENBERGER, D.; SILVA DA ROSA, F. Controllership functions: an analysis in the brazilian scenario. Revista Brasileira de Gestão e Negócios, São Paulo, v. 15, n. 47, p. 283-299, 2013.

MELLER, A. J.; LOPES, D. G.; LUNKES, R. J. As funções da controladoria sob a perspectiva dos estágios de desenvolvimento de Weber. In: $5 .^{\circ}$ Congresso UFSC de Controladoria e Finanças \& Iniciação Científica em Contabilidade. Anais... UFSC. Florianópolis, 2014.

MONTEIRO, R. P. Análise do sistema de controle interno no Brasil: objetivos, importância e barreira para sua implantação. Revista Contemporânea de Contabilidade, Florianópolis, v. 12, n. 25, p. 159-188, jan./abr. 2015.

PELEIAS, I. R. et al. Dez anos de pesquisa científica em controladoria no Brasil (1997 a 2006). Revista de Administração e Inovação. USP. São Paulo, v. 7, n. 1, p. 193-217, 2010.

PISCITELLI, R. B.; TIMBO, M. Z. F. ROSA, M. B. Contabilidade pública: uma abordagem da administração financeira pública. 13. ed. São Paulo: Atlas, 2014.

VILHENA, PREFEITURA MUNICIPAL DE. Lei n. 1.622 de 29 de abril de 2003. Dispõe sobre a criação da Controladoria Geral do Município de Vilhena, estabelece competência, institui o Sistema Integrado de Controle Interno e acresce dispositivos ao art. 24 da Lei n $^{\circ}$ 1.103, de 21 de setembro de 1999, e dá outras providências. Disponível em: <http://200.101.83.70:8080/portaltransparencia/>. Acesso em: 6 nov. 2015.

ROZO, J. D. Relação entre mecanismos de governança corporativa e medidas de performance econômica das empresas brasileiras integrantes do Índice Brasil da Bolsa de Valores de São Paulo. São Paulo, 2003. Tese (Doutorado em Controladoria e Contabilidade) - Programa de Pós-Graduação em Controladoria e Contabilidade, Departamento de Contabilidade e Atuária, Faculdade de Economia, Administração e Contabilidade da Universidade de São Paulo.

SCHMIDT, P.; SANTOS, J. L.; MARTINS, M. A. S. Manual de controladoria. São Paulo: Atlas, 2014.

SILVA, L. M. Contabilidade governamental: um enfoque administrativo 7. ed. São Paulo: Atlas, 2004.

SILVA, M. M. Curso de auditoria governamental. São Paulo: Atlas, 2012.

SILVA, N. R.; CARNEIRO, A. F.; RAMOS, E. G. Controladoria do setor público: uma comparação entre as leis de criação em quatro dos maiores municípios de Rondônia e a literatura. Revista Evidenciação Contábil \& Finanças, João Pessoa, UFPB, v. 3, n. 2, p. 7387, mai./ago. 2015.

SLOMSKI, V. Teoria do agenciamento no estado - uma evidenciação da distribuição de renda econômica produzida pelas entidades públicas de administração direta. São Paulo, 1999. Tese (Doutorado em Ciências Contábeis) - Programa de Pós-Graduação em Ciências 
Contábeis, Departamento de Contabilidade e Atuária, Faculdade de Economia, Administração e Contabilidade da Universidade de São Paulo.

Manual de contabilidade pública: um enfoque na contabilidade municipal. 2. ed. São Paulo: Atlas, 2003.

Controladoria e governança na gestão pública. São Paulo: Atlas, 2007.

SUZART, J. A. S.; MARCELINO, C. V.; ROCHA, J. S. As instituições brasileiras de controladoria pública - teoria versus prática. Contabilidade, Gestão e Governança, Brasília, v. 14, n. 1, p. 44-56, 2011.

THIOLLENT, M. Pesquisa-ação nas organizações. 2.ed. São Paulo: Atlas, 2009.

TCE-RO - Tribunal de Contas do Estado de Rondônia. Decisão Normativa n. 001/2015/TCE-RO de 25 de setembro de 2015. Estabelece diretrizes gerais sobre a implementação e operacionalização do sistema de controle interno para os entes jurisdicionados.Disponível em: <http://www.tce.ro.gov.br/tribunal/legislacao/arquivos/DeNo001-2015.pdf>. Acesso em: 6 nov. 2015.

TRIPP, D. Pesquisa-ação: uma introdução metodológica. Educação e Pesquisa, São Paulo, v. 31, n. 3, p. 443-466, 2005.

VERGARA, S. C. Projetos e relatórios de pesquisa em administração. 15. ed. São Paulo: Atlas, 2014.

WRIGHT, G. A.; CALlADO, A. L. C.; MELO, M. M. D. As funções da controladoria no setor público: a percepção de quem faz a Controladoria Geral da União. In: $13 .^{\circ}$ Congresso USP de Controladoria e Contabilidade. Anais... USP. São Paulo, 2013. 